DOI: 10.25557/0031-2991.2021.03.64-72

(с) Александрова Н.П., Погонченкова И.В., 2021

удк 616.13-008.64

Александрова Н.П., Погонченкова И.В.

Действие преформированных физических факторов на реологические свойства крови у больных с хронической постэмболической легочной гипертензией

ГБУз «Московский научно-практический центр медицинской реабилитации, восстановительной и спортивной медицины» Департамента здравоохранения города Москвы,

105120, Москва, Россия, ул. Земляной Вал, д. 53

Введение. Основу взаимодействия физических факторов и организма составляют электрические и биоэнергетические процессы, вызывающие изменения показателей центральной и периферической гемодинамики, обменных процессов, трофики, дыхания, реактивности и сопротивляемости организма. К таким физическим факторам, в частности, относятся электромагнитные колебания оптического излучения или фототерапия. Цель исследования - оценка эффективности воздействия коротковолнового излучения (фотогемотерапии, ФГТ) и ультрафиолетового (УФ) облучения крови на ее реологические свойства в комплексной терапии больных хронической постэмболической легочной гипертензией (ХПЛГ).

Методика. Проведено комплексное клинико-лабораторное обследование 64 пациентов (30 женщин и 34 мужчины), поступивших в клинику с симптомами хронической легочной недостаточности, развившейся после перенесенной тромбоэмболии легочной артерии. Больные ХПЛг были распределены в 3 группы: 1-ю (контрольную) группу составили 15 пациентов, получавшие только базисное лечение; 2-ю (экспериментальную) группу - 26 больных, получавшие базисную терапию в комплексе с ФГТ; 3-ю (экспериментальную) группу - 23 пациента, которые получали базисную терапию в сочетании с воздействием на кровь УФ облучения. Для ФГТ синим светом и УФ воздействия на кровь применяли аппараты АФС-Соларис (Россия) со светодиодами, излучающими синий свет с длиной волны $450 \pm 10$ нм, и УФ лучи с длиной волны $365 \pm 10$ нм. Исследовали вязкость крови на ротационном вискозиметре RotoVisco-100 (Наaке GmbH, Германия) в диапазоне скоростей сдвига от 1 до $150 \mathrm{c}^{-1}$, агрегацию эритроцитов на колориметре-нефелометре ФЭК-56 М (Россия), показатель гематокрита на гематокритной центрифуге (Autocrit, США).

Результаты. У больных 1-й группы после базисного медикаментозного лечения отсутствовали статистически значимые изменения вязкости крови, агрегации эритроцитов и показателя гематокрита. У пациентов как 2-й, так и 3-й группы выявлены статистически значимые изменения реологических свойств крови: снижение вязкости крови, агрегации эритроцитов, показателя гематокрита.

Заключение. Оптическое излучение синего света имеет выраженное физиологическое воздействие: вызывает медленный, но пролонгированный положительный эффект на реологические свойства крови. УФ облучение при воздействии на кровь также способствует улучшению гемореологии и циркуляции крови и активирует рудиментарные механизмы, запускающие адаптационные системы организма, ранее не функционирующие.

Ключевые слова: фотогемотерапия; реология крови; микроциркуляция; оптическое излучение; синий свет

Для цитирования: Александрова Н.П., Погонченкова И.В. Действие преформированных физических факторов на реологические свойства крови у больных хронической постэмболической легочной гипертензией. Патологическая физиология и экспериментальная терапия. 2021; 65(3): 64-72.

DOI: 10.25557/0031-2991.2021.03.64-72

Участие авторов: концепция и дизайн исследования, сбор и обработка материала - Александрова Н.П., Погонченкова И.В.; статистическая обработка результатов - Александрова Н.П.; написание текста - Александрова Н.П.; редактирование Погонченкова И.В.

Для корреспонденции: Александрова Наталья Павловна, e-mail: anatalyp@yandex.ru

Финансирование. Исследование не имело спонсорской поддержки.

Конфликт интересов. Авторы заявляют об отсутствии конфликта интересов.

Поступила 20.03.2020

Принята к печати 30.06.2021

Опубликована 30.09.2021 
DOI: 10.25557/0031-2991.2021.03.64-72

\section{Aleksandrova N.P., Pogonchenkova I.V. \\ Effects of preformed physical factors on blood rheology in patients with chronic post-embolic pulmonary hypertension}

Moscow Centre for Research and Practice in Medical Rehabilitation, Restorative and Sports Medicine, Zemlyanoi Val St. 53, Moscow 105120, Russian Federation

Introduction. Electrical and bioenergetic processes that cause changes in central and peripheral hemodynamics, metabolic processes, trophism, respiration, reactivity, and body resistance are the basis of interaction between physical factors and the body. Such physical factors include, in particular, electromagnetic oscillations of the optical radiation or phototherapy. Aim: to assess the effectiveness of short-wave radiation (photohemotherapy, PHT) and ultraviolet (UV) irradiation of blood on its rheology in the complex treatment of chronic post-embolic pulmonary hypertension (CPPH).

Methods. 64 patients (30 women and 34 men) with symptoms of chronic pulmonary insufficiency secondary to pulmonary embolism underwent a comprehensive clinical and laboratory examination. CPPH patients were divided into 3 groups: the $1^{\text {st }}$ (control) group consisting of 15 patients who received only a basic treatment; the $2^{\text {nd }}$ (experimental) group including 26 patients who received a basic therapy combined with PHT; and the $3^{\text {rd }}$ (experimental) group consisting of 23 patients who received a basic therapy combined with UV irradiation of blood. AFS-Solaris devices (Russia) producing light-emitting diode-derived blue light with a wavelength of $450 \pm 10 \mathrm{~nm}$ were used for FGT, and UV rays with a wavelength of $365 \pm 10 \mathrm{~nm}$ were used for the UV exposure of blood. Blood viscosity was measured on a RotoVisco-100 (Нааке GmbH, Germany) rotational viscometer at shear rates ranging from 1 to $150 \mathrm{~s}^{-1}$; erythrocyte aggregation was studied with a FEK-56 M (Russia) colorimeter-nephelometer; and hematocrit was measured with a hematocrit centrifuge (Autocrit, USA).

Results. There were no statistically significant changes in blood viscosity, erythrocyte aggregation, or hematocrit values in the $1^{\text {st }}$ group after the basic treatment. Statistically significant changes in blood rheology parameters observed in both the $2^{\text {nd }}$ and $3^{\text {rd }}$ groups included decreases in blood viscosity, erythrocyte aggregation, and hematocrit values.

Conclusion. Optical irradiation with blue light exerted a pronounced physiological effect evident as a slow but long-standing positive influence on blood rheology parameters. The UV irradiation of blood also improved hemorheology and blood circulation and activated rudimentary mechanisms triggering previously non-functional adaptive systems.

Keywords: photohemotherapy; blood rheology; microcirculation; optical radiation; blue light

For citation: Aleksandrova N.P., Pogonchenkova I.V. Effects of preformed physical factors on blood rheology in patients with chronic post-embolic pulmonary hypertension. Patologicheskaya Fiziologiya i Eksperimental naya terapiya. (Pathological Physiology and Experimental Therapy, Russian Journal). 2021; 65(3) 64-72. (in Russian)

DOI: 10.25557/0031-2991.2021.03.64-72

Contribution: concept and design of the study, collection and processing of the material - Aleksandrova N.P., Pogonchenkova I.V.;
statistical processing - Aleksandrova N.P.; writing the text - Aleksandrova N.P.; editing - Pogonchenkova I.V.

For correspondence: Natalya P. Aleksandrova, Doctor of Biological Sciences, Professor, Leading Researcher, Department of Medical Rehabilitation, Moscow Centre for Research and Practice in Medical Rehabilitation, Restorative and Sports Medicine, Zemlyanoi Val St. 53, Moscow 105120, Russian Federation, e-mail: anatalyp@yandex.ru

Acknowledgment. The study had no sponsorship.

Conflict of interest. The authors declare no conflict of interest.

Information about the authors:

Aleksandrova N.P., https://orcid.org/0000-0003-4647-4351

Pogonchenkova I.V., https://orcid.org/0000-0001-5123-5991

Received: 20.03.2020

Accepted: 30.06 .2021

Published: 30.09 .2021

\section{Введение}

Реакция организма на воздействие физических факторов обеспечивается различными системами организма и выражается в различных изменениях показателей центральной и периферической гемодинамики, обменных процессов, трофики, дыхания, реактивности и сопротивляемости организма.

Лечебный эффект физического фактора зависит от особенностей распределения его энергии и от фи- зических свойств тканей-мишеней, осуществляющих поглощение энергии физического фактора. Лечебные физические факторы можно строго дозировать по значительному числу параметров, что способствует оптимальной индивидуализации терапевтических воздействий. К таким физическим факторам, в частности, относятся электромагнитные колебания оптического диапазона или фототерапия. 
DOI: 10.25557/0031-2991.2021.03.64-72

В последнее время в литературе достаточно активно дискутируются вопросы применения фотогемотерапии (ФГТ) - коротковолнового спектра оптического излучения и ультрафиолетового (УФ) облучения крови как вариант немедикаментозного метода коррекции различных гомеостатических расстройств, сопровождающих многочисленные заболевания и состояния [1-3]. Вариантом фототерапии является фотогемотерапия - воздействие на кровь пациента оптическим излучением экстракорпорально или внутрисосудисто.

В соответствии с синдромно-патогенетической классификацией физических методов лечения по Г.Н. Пономаренко фототерапия относится к органо-неспецифическим методам, купирующим преобладающие синдромы заболевания: болевой, воспалительный, интоксикационный, метаболический, дистрофический и иммунной дисфункции [4].

Хроническая постэмболическая легочная гипертензия (ХПЛГ) - это патологическое состояние, обусловленное хронической окклюзией или стенозом легочного артериального русла после тромбоэмболии легочных артерий (ТЭЛА), которое приводит к развитию хронического легочного сердца. Легочная эмболия - частое заболевание: ежегодно регистрируется 35-40 случаев на 100 тыс. человек [5-9].

Постэмболическая хроническая редукция части сосудистого русла легких является инициирующим фактором увеличения общего легочного сопротивления. Вследствие нарушения перфузионно-вентиляционных отношений и падения сердечного выброса развивается артериальная гипоксемия. Адаптационной реакцией организма на хроническую гипоксию является активация эритропоэза с дальнейшим развитием у больных состояния гипервязкости крови и синдрома гемореологических расстройств [10].

Поэтому, несмотря на значительное количество клинических и экспериментальных исследований этиологии и патогенеза ХПЛГ, проблема выбора методов ее лечения вызывает целый ряд затруднений.

Актуальность изучения состояния микро- и макрогемодинамики и поиск новых медикаментозных средств для лечения ХПЛГ определяется снижением насосной функции сердечной мышцы, которое имеет часто значительный и необратимый характер и приводит к тяжелой недостаточности кровообращения, причиной которой среди прочих являются и гемореологические нарушения [11].

Однако реологические свойства крови на практике редко рассматриваются при оценке кровообращения, особенно в условиях патологии. Это объясняется тем, что такие изменения во многом определяются гидро- динамическими факторами и геометрией сосудистого русла, которые для разных его участков неодинаковы. Однако даже общие представления о реологических свойствах крови, направленности их изменений в условиях патологии и применения терапевтических мероприятий могут дать немало для трактовки расстройств кровообращения и оценки механизмов их коррекции.

Ранее проведенные нами исследования показали, что ХПЛГ сопровождается гемореологическими расстройствами, проявляющимися в нарушении структуры кровотока, сгущении крови за счет полицитемии и увеличения количества и размеров циркулирующих эритроцитов [12]. Все это может значительно изменить характеристики кровотока и усугубить течение основного заболевания [13].

В настоящее время ни одно из применяемых для лечения ХПЛГ медикаментозных средств не влияет в должной мере на вязкость крови, величину гематокрита и поведение эритроцитов в потоке. Это объясняется тем, что гемореологические нарушения имеют выраженный инертный характер и весьма трудно поддаются коррекции.

Цель исследования - оценка эффективности воздействия коротковолнового излучения (ФГТ) и УФ облучения крови на ее реологические свойства в комплексной терапии больных ХПЛГ.

\section{Методика}

В ГБУЗ «МНПЦ МРВСМ ДЗМ» г. Москвы проведено клинико-лабораторное обследование 64 пациентов (30 женщин и 34 мужчины) с симптомами хронической легочной недостаточности, развившейся после перенесенной тромбоэмболии легочных артерий. Исследование выполнено в соответствии с этическими нормами Хельсинкской декларации Всемирной медицинской ассоциации $(1964,2004)$ и письменного добровольного информированного согласия всех пациентов. Работа одобрена этической комссией ГБУЗ. Давность заболевания у всех больных составила от 3 мес до 15 лет (в среднем -45 мес). Возраст больных составил $47 \pm 6,6$ года. Из сопутствующих заболеваний у $70 \%$ пациентов отмечена посттромботическая болезнь нижних конечностей; у 15 человек в анамнезе - операция тромбинтимэктомии из легочной артерии. Ангиографический индекс Миллера у всех больных составил в среднем 19,6 балла (13-30 баллов), сканографический перфузионный дефицит в среднем - 30,3\% (16-69\%), давление в легочной артерии в среднем - 4 мм рт. ст., систолическое давление в среднем - 73 мм рт. ст.

При поступлении больные были обследованы методами ангиопульмонографии на аппарате Tridoros- 
optimatic 1000 (Siemens, ФРГ), перфузионного сканирования легких, которое выполнялось на двухдатчиковом сканере Scintimat-2 (Siemens, ФРГ), электрокардиографии на аппарате Mingograph-81 (Siemens, ФРГ), эхокардиографии на ультразвуковых аппаратах Ecoline-21 (США) и Aloka-28C (Hitachi, Япония).

Больные ХПЛГ были распределены в 3 группы: 1-ю (контрольную) группу составили 15 пациентов, получавшие только базисное лечение; 2-ю (экспериментальную) группу - 26 больных, получавшие базисную терапию в комплексе с ФГТ; 3-ю (экспериментальную) группу - 23 пациента, которые получали базисную терапию в сочетании с воздействием на кровь УФ облучения.

В состав базисной терапии входили нитросорбид, верошпирон, фуросемид, нифедипин, панангин и дезагреганты. В качестве основных антитромбоцитарных препаратов назначали ацетилсалициловую кислоту, пентоксифиллин, простагландин Е1; в качестве антикоагулянтов применяли в небольших дозах гепарин, низкомолекулярные гепарины, не требующие постоянного лабораторного мониторинга; реополиглюкин; спазмолитики (папаверин, дротаверин).

Для ФГТ синим светом и УФ воздействия на кровь применяли аппарат АФС-Соларис (Россия) со светодиодами, излучающими синий свет с длиной волны $450 \pm 10$ нм, и УФ лучи с длиной волны $365 \pm 10$ нм (регистрационное удостоверение № ФСР 2010/08725 от 30.08.2010). Волоконно-оптические насадки вводили в локтевую вену пациента; мощность на конце световодов составляла $1,0-1,5$ мВт. Воздействие продолжалось 30 мин, проводилось через день и в целом составляло 7 процедур.

Для исследования реологических свойств крови использовали комплекс общепринятых методов: вязкость крови измеряли на ротационном вискозиметре Rotovisco-100 (Нааке, Германия) в диапазоне скоростей сдвига от 1 до $150 \mathrm{c}^{-1}$, что соответствовало условиям венозного и артериального кровотока; агрегацию эритроцитов определяли на колориметре-нефелометре ФЭК-56 М (Россия); показатель гематокрита измеряли на гематокритной центрифуге (Autocrit, США).

Итоговые данные анализировали отдельно для мужчин и для женщин, так как физиологические значения гематокрита и гемоглобина имеют гендерные различия: в норме женщины имеют более низкий уровень гематокрита и, соответственно, более низкую вязкость крови, чем мужчины. Для определения нормальных значений реологических свойств крови было обследовано 15 практически здоровых лиц (7 женщин

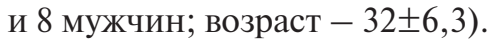

Статистический анализ данных осуществляли посредством статистического пакета Statistica 10.0 (StatSoft Inc., США) с соблюдением принципов и требований к статистической обработке материала в биологических и медицинских исследованиях. Для анализа соответствия вида распределения признака закону нормального распределения применяли критерий Шапиро-Уилка. Для описания количественных данных использовали среднее арифметическое (М) и стандартную ошибку среднего (m). Различия в соответствии с критериями Стьюдента считали статистически значимыми при $p<0,05$.

\section{Результаты и обсуждение}

На первом этапе исследования при изучении гемореологического статуса при поступлении в стационар у всех больных ХПЛГ до лечения установлены выраженные нарушения реологических свойств крови (табл. 1, 2).

Как следует из представленных в табл. 1 данных, у мужчин- пациентов с ХПЛГ все вязкостные параметры значительно превышали нормальные: структурная вязкость - на $42 \%$, динамическая - на $32 \%$ и на $28 \%$, соответственно. Величина гематокрита превышала нормальные значения на $14 \%$, а агрегация эритроцитов - на $58 \%$.

У женщин (табл. 2) структурная вязкость крови превышала нормальную в среднем на $36 \%$, динамическая - на $30 \%$ и на 24\%, соответственно; показатель гематокрита также как у мужчин, был повышен на 14\%, агрегация эритроцитов - на $51 \%$.

Анализ степени участия каждого отдельного гемореологического показателя в повышении вязкости крови, обусловливающего в целом текучесть крови при ХПЛГ, выявил, что доминирующими параметрами, влияющими на рост вязкости крови при данном заболевании, являются повышенный показатель гематокрита и усиленная агрегация эритроцитов. Полицитемия у больных ХПЛГ является ответной реакцией организма на хроническое кислородное голодание и тем более опасна для данной категории больных , что значительно возросшее у них в кровотоке количество агрегированных эритроцитов может вызвать их секвестрацию в селезенке, печени и в легких, что сопровождается еще большим дефицитом кислорода в органах и тканях.

Хроническая легочная недостаточность любого генеза (эмфизема, фиброз, хронический бронхит, эмболия легочной артерии и др.) неизбежно вызывает гемореологические нарушения, которые запускаются специфическими механизмами, обусловливающи- 
ми многофакторность патогенеза ХПЛГ. Поэтому гемореологические расстройства носят такой же устойчивый, инертный и хронический характер, как и само заболевание ХПЛГ, и зависят от того, в какой степени активности на момент исследования находятся те специфические механизмы, которые спровоцировали эти нарушения.

В частности, между вязкостью крови и значением показателей легочной артериальной гемодинамики существует тесная взаимосвязь. Повышение вязкости крови у больных ХПЛГ происходит соразмерно увеличению сосудистого сопротивления и росту легочного артериального давления. Подтверждением сказанному является ранее проведенный в этом направлении корреляционный анализ, который показал наличие тесных корреляционных связей: между вязкостью крови и величиной перфузионного дефицита у больных
ХПЛГ ( $r=0,653)$, между вязкостью и параметрами легочного сосудистого сопротивления $(r=0,742)$, между вязкостью и средним давлением в легочной артерии $(r=0,751)$, между вязкостью и сердечным индексом $(r=0,548)$ и наличие слабой корреляционной связи $(r=0,243)$ с длительностью заболевания $(p<0,05)[14]$. Поэтому синдром гипервязкости крови при ХПЛГ помимо собственно реологических факторов, определяющих данный показатель, в еще большей степени обусловлен объемом поражения сосудов легких и в меньшей степени - длительностью заболевания.

На следующем этапе исследования определяли реологический статус больных ХПЛГ по группам. У больных 1-й группы, которые получали только базисную медикаментозную терапию, после лечения отсутствовали существенные изменения изученных параметров по сравнению с показателями до лечения (табл. 3).

Реологические характеристики крови у мужчин с хронической постэмболической легочной гипертензией, $(M \pm m)$ Blood rheological characteristics in men with chronic post-embolic pulmonary hypertension, $(M \pm m)$

\begin{tabular}{|c|c|c|c|c|c|}
\hline $\begin{array}{c}\text { Группы } \\
\text { обследованных }\end{array}$ & $\begin{array}{c}\text { Вязкость крови } \\
\text { (сП) при скорости } \\
\text { сдвига } 1 \mathrm{c}^{-1}\end{array}$ & $\begin{array}{c}\text { Вязкость крови } \\
\text { (сП) при скорости } \\
\text { сдвига } 9 \mathrm{c}^{-1}\end{array}$ & $\begin{array}{c}\text { Вязкость крови } \\
\text { (сП) при скорости } \\
\text { сдвига } 150 \mathrm{c}^{-1}\end{array}$ & $\begin{array}{c}\text { Показатель } \\
\text { гематокрита (\%) }\end{array}$ & $\begin{array}{c}\text { Агрегация } \\
\text { эритроцитов (\%) }\end{array}$ \\
\hline $\begin{array}{l}\text { 1-я группа } \\
(n=8)\end{array}$ & $28,6 \pm 3,1^{*}$ & $8,35 \pm 0,24^{*}$ & $4,37 \pm 0,19^{*}$ & $50,0 \pm 1,12^{*}$ & $54,9 \pm 3,8^{*}$ \\
\hline $\begin{array}{l}\text { 2-я группа } \\
(n=14)\end{array}$ & $26,9 \pm 2,4^{*}$ & $8,49 \pm 0,32 *$ & $4,41 \pm 0,11^{*}$ & $49,4 \pm 1,32 *$ & $57,7 \pm 4,5^{*}$ \\
\hline $\begin{array}{l}\text { 3-я группа } \\
(n=12)\end{array}$ & $27,2 \pm 2,7^{*}$ & $8,47 \pm 0,22 *$ & $4,29 \pm 0,21^{*}$ & $48,9 \pm 1,02 *$ & $53,4 \pm 4,7^{*}$ \\
\hline
\end{tabular}

Примечание. ${ }^{*}-p<0,05$ - различия статистически значимы по сравнению с нормальными значениями.

Note. ${ }^{*}-p<0.05-$ the differences are statistically significant compared to normal values.

Реологические характеристики крови у женщин с хронической постэмболической легочной гипертензией, ( $M \pm m$ ) Blood rheological characteristics in women with chronic postembolic pulmonary hypertension, $(M \pm m)$

\begin{tabular}{|c|c|c|c|c|c|}
\hline Группы обследованных & $\begin{array}{c}\text { Вязкость крови } \\
\text { (сП) при скорости } \\
\text { сдвига } 1 \mathrm{c}^{-1} \\
\end{array}$ & $\begin{array}{c}\text { Вязкость крови } \\
\text { (сП) при скорости } \\
\text { сдвига } 9 \mathrm{c}^{-1} \\
\end{array}$ & $\begin{array}{c}\text { Вязкость крови } \\
\text { (сП) при скорости } \\
\text { сдвига } 150 \mathrm{c}^{-1} \\
\end{array}$ & $\begin{array}{c}\text { Показатель } \\
\text { гематокрита (\%) }\end{array}$ & $\begin{array}{c}\text { Агрегация } \\
\text { эритроцитов (\%) }\end{array}$ \\
\hline $\begin{array}{l}\text { 1-я группа } \\
(n=7)\end{array}$ & $23,8 \pm 2,2^{*}$ & $7,7 \pm 0,2^{*}$ & $3,9 \pm 0,3^{*}$ & $45,6 \pm 1,1^{*}$ & $46,5 \pm 1,8^{*}$ \\
\hline $\begin{array}{l}\text { 2-я группа } \\
(n=12)\end{array}$ & $25,1 \pm 1,3^{*}$ & $7,2 \pm 0,1^{*}$ & $3,7 \pm 0,5^{*}$ & $45,5 \pm 1,1^{*}$ & $48,5 \pm 2,3^{*}$ \\
\hline $\begin{array}{l}\text { 3-я группа } \\
(n=11)\end{array}$ & $24,9 \pm 2,5^{*}$ & $7,43 \pm 0,15^{*}$ & $3,9 \pm 0,2 *$ & $45,8 \pm 1,2^{*}$ & $49,9 \pm 3,3^{*}$ \\
\hline
\end{tabular}

Примечание. * $-p<0,05$ - различия статистически значимы по сравнению с нормальными значениями. Note. ${ }^{*}-p<0.05-$ the differences are statistically significant compared to normal values. 
В то же время следует отметить некоторую тенденцию к снижению агрегации эритроцитов у больных этой группы под действием пентоксифилина и аспирина, которые больные получали в качестве антиагрегантов.

Несколько иная картина выявлена в параметрах гемореологии у больных ХПЛГ 2-й и 3-й эксперимен- тальных групп после базисного лечения в сочетании с ФГТ и УФ облучением крови (табл. 4, 5).

Так у пациентов ХПЛГ 2-й группы, как у мужчин, так и у женщин, после базисной терапии в сочетании с оптическим излучением синего света было установлено статистически значимое снижение вязкостных

Таблича 3/Table 3

Реологические характеристики крови у больных хронической постэмболической легочной гипертензией 1-й (контрольной) группы до и после курса базисной медикаментозной терапии, $(M \pm m)$

Blood rheological characteristics in patients with chronic post-embolic pulmonary hypertension of the $1^{\text {st }}$ (control group) before and after the course of basic therapy, $(M \pm m)$

\begin{tabular}{|c|c|c|c|c|c|c|c|c|c|c|}
\hline \multirow{2}{*}{$\begin{array}{c}\text { Группы } \\
\text { обследованных }\end{array}$} & \multicolumn{2}{|c|}{$\begin{array}{c}\text { Вязкость крови (сП) } \\
\text { при скорости сдвига } \\
1 \mathrm{c}^{-1} \\
\end{array}$} & \multicolumn{2}{|c|}{$\begin{array}{c}\text { Вязкость крови (сП) } \\
\text { при скорости сдвига } \\
9 \mathrm{c}^{-1} \\
\end{array}$} & \multicolumn{2}{|c|}{$\begin{array}{c}\text { Вязкость крови (сП) } \\
\text { при скорости сдвига } \\
150 \mathrm{c}^{-1} \\
\end{array}$} & \multicolumn{2}{|c|}{$\begin{array}{c}\text { Показатель } \\
\text { гематокрита (\%) }\end{array}$} & \multicolumn{2}{|c|}{$\begin{array}{c}\text { Агрегация } \\
\text { эритроцитов (\%) }\end{array}$} \\
\hline & до & после & до & после & до & после & до & после & до & после \\
\hline \multicolumn{11}{|c|}{ Мужчины: } \\
\hline $\begin{array}{l}\text { 1-я группа } \\
(n=8)\end{array}$ & $28,6 \pm 3,1$ & $27,8 \pm 2,7$ & $\begin{array}{c}8,35 \pm \\
0,24^{*}\end{array}$ & $\begin{array}{c}8,12 \pm \\
0,11^{*}\end{array}$ & $\begin{array}{c}4,37 \pm \\
0,19\end{array}$ & $\begin{array}{c}4,03 \pm \\
0,12\end{array}$ & $\begin{array}{c}50,0 \pm 1,1 \\
*\end{array}$ & $\begin{array}{c}49,2 \pm \\
1,1^{*}\end{array}$ & $\begin{array}{c}45,6 \pm \\
1,09\end{array}$ & $\begin{array}{c}40,1 \pm \\
1,06\end{array}$ \\
\hline \multicolumn{11}{|c|}{ Женщины: } \\
\hline $\begin{array}{l}1 \text {-я группа } \\
(n=7)\end{array}$ & $21,8 \pm 2,2$ & $20,3 \pm 1,6$ & $7,7 \pm 0,2$ & $7,6 \pm 0,3$ & $3,9 \pm 0,3$ & $3,8 \pm 0,2$ & $45,6 \pm 1,1$ & $45,0 \pm 1,1$ & $42,5 \pm 1,8$ & $39,3 \pm 1,3$ \\
\hline $\begin{array}{l}\text { Нормальные } \\
\text { значения }(n=7)\end{array}$ & \multicolumn{2}{|c|}{$18,1 \pm 1,1$} & \multicolumn{2}{|c|}{$5,7 \pm 0,1$} & \multicolumn{2}{|c|}{$3,1 \pm 0,1$} & \multicolumn{2}{|c|}{$41,20 \pm 0,01$} & \multicolumn{2}{|c|}{$32,5 \pm 1,3$} \\
\hline
\end{tabular}

Примечание. * $-p<0,05$ - различия статистически значимы по сравнению с исходными (до лечения) значениями.

Note. ${ }^{*}-p<0.05-$ the differences are statistically significant compared to baseline values (before therapy).

Таблича 4/Table 4

Реологические характеристики крови у больных хронической постэмболической легочной гипертензией 2-й (экспериментальной) группы до и после курса базисной терапии в сочетании с фотогемотерапией синим светом, $(M \pm m)$

Blood rheological characteristics in patients with chronic postembolic pulmonary hypertension of the $2^{\text {nd }}$ (experimental) group before and after the course of basic therapy combined with blue light photogemotherapy, $(M \pm m)$

\begin{tabular}{|c|c|c|c|c|c|c|c|c|c|c|}
\hline \multirow{3}{*}{$\begin{array}{c}\text { Группы } \\
\text { обследованных }\end{array}$} & \multicolumn{2}{|c|}{$\begin{array}{c}\text { Вязкость крови } \\
\text { (сП) при скорости } \\
\text { сдвига } 1 \mathrm{c}^{-1} \\
\end{array}$} & \multicolumn{2}{|c|}{$\begin{array}{c}\text { Вязкость крови } \\
\text { (сП) при скорости } \\
\text { сдвига } 9 \mathrm{c}^{-1} \\
\end{array}$} & \multicolumn{2}{|c|}{$\begin{array}{c}\text { Вязкость крови } \\
\text { (сП) при скорости } \\
\text { сдвига } 150 \mathrm{c}^{-1} \\
\end{array}$} & \multicolumn{2}{|c|}{$\begin{array}{c}\text { Показатель } \\
\text { гематокрита (\%) }\end{array}$} & \multicolumn{2}{|c|}{$\begin{array}{c}\text { Агрегация } \\
\text { эритроцитов (\%) }\end{array}$} \\
\hline & до & после & до & после & до & после & до & после & до & после \\
\hline & \multicolumn{2}{|c|}{ лечения } & \multicolumn{2}{|c|}{ лечения } & \multicolumn{2}{|c|}{ лечения } & \multicolumn{2}{|c|}{ лечения } & \multicolumn{2}{|c|}{ лечения } \\
\hline \multicolumn{11}{|c|}{ Мужчины: } \\
\hline $\begin{array}{l}\text { 2-я группа } \\
(n=14)\end{array}$ & $\begin{array}{c}26,9 \pm \\
2,4 \\
\end{array}$ & $\begin{array}{c}23,5 \pm \\
1,8^{*} \\
\end{array}$ & $\begin{array}{c}8,49 \pm \\
0,32 \\
\end{array}$ & $\begin{array}{c}7,27 \pm \\
0,22^{*} \\
\end{array}$ & $\begin{array}{c}4,41 \pm \\
0,11 \\
\end{array}$ & $\begin{array}{c}3,74 \pm \\
0,21^{*} \\
\end{array}$ & $\begin{array}{c}49,40 \pm \\
1,32 \\
\end{array}$ & $\begin{array}{c}46,90 \pm \\
1,12 \\
\end{array}$ & $\begin{array}{c}57,7 \pm \\
4,5 \\
\end{array}$ & $\begin{array}{c}48,2 \pm \\
4,5\end{array}$ \\
\hline \multicolumn{11}{|c|}{ Женщины: } \\
\hline $\begin{array}{l}\text { 2-я группа } \\
(n=12)\end{array}$ & $\begin{array}{c}25,1 \pm \\
1,3\end{array}$ & $\begin{array}{c}22,3 \pm \\
2,2^{*}\end{array}$ & $\begin{array}{c}7,21 \pm \\
0,11\end{array}$ & $\begin{array}{c}6,13 \pm \\
0,21^{*}\end{array}$ & $\begin{array}{c}3,74 \pm \\
0,50\end{array}$ & $\begin{array}{c}3,34 \pm \\
0,22 *\end{array}$ & $\begin{array}{c}45,50 \pm \\
1,07\end{array}$ & $\begin{array}{c}43,10 \pm \\
1,12\end{array}$ & $\begin{array}{c}41,9 \pm \\
3,3\end{array}$ & $\begin{array}{r}32,8 \pm \\
2,1^{*}\end{array}$ \\
\hline $\begin{array}{l}\text { Нормальные } \\
\text { значения }(n=7)\end{array}$ & \multicolumn{2}{|c|}{$18,1 \pm 1,1$} & \multicolumn{2}{|c|}{$5,7 \pm 0,1$} & \multicolumn{2}{|c|}{$3,1 \pm 0,1$} & \multicolumn{2}{|c|}{$41,20 \pm 0,01$} & \multicolumn{2}{|c|}{$32,5 \pm 1,3$} \\
\hline
\end{tabular}

Примечание. ${ }^{*}-p<0,05$ - различия статистически значимы по сравнению с исходными (до лечения) значениями.

Note. ${ }^{*}-p<0.05$ - the differences are statistically significant compared to baseline values (before therapy). 
параметров крови при всех скоростях сдвига, соответствующих различным уровням артериального и венозного кровообращения. Вязкость крови у мужчин снизилась на 13-15\%, агрегация эритроцитов - на 17\%, показатель гематокрита - на 5\%. У женщин после ФГТ все вязкостные параметры снизились на 11-15\%; агрегация эритроцитов - на 22\%, показатель гематокрита - на 5\%.

Таким образом, применение ФГТ в комплексной терапии больных ХПЛГ продемонстрировало значимую эффективность воздействия коротковолнового излучения синего света на реологический статус больных с данным заболеванием.

Анализ результатов, полученных у больных ХПЛГ 3-й группы, которым в комплексе с базисной терапией проводили УФ облучение крови, продемонстрировал изменения ее реологических свойств, аналогичные тем, что были получены во 2-й группе пациентов (табл. 5).

Также, как и во 2-й группе больных ХПЛГ, которым в комплексе с базисной терапией проводили ФГТ синим светом, у пациентов 3-й группы, у которых осуществлялось УФ облучение крови, вязкостные показатели при всех скоростях сдвига, отражающие характеристики кровотока в артериальном и венозном звене кровообращения, снизились в среднем на $12-17 \%$ как у мужчин, так и у женщин. Также существенно снизилась агрегация эритроцитов: у мужчин - на 9\%, у женщин - на 11\%. В отличие от ФГТ, после УФ об- лучения крови показатель гематокрита возрос у мужчин 3-й группы на 4\%, а у женщин - на 3\%, что свидетельствовало об умеренной вторичной полицитемии.

Последнее обстоятельство объясняется тем, что одним из механизмов воздействия УФ лучей на организм является стимуляция эритропоэза и, как следствие, повышение количества циркулирующих эритроцитов. Этим же можно объяснить меньшую эффективность воздействия УФ облучения на все вязкостные показатели у больных 3-й группы по сравнению с действием ФГТ у пациентов 2-й группы.

Нужно отметить тот факт, что даже при высокой эффективности воздействия оптического излучения синего света и УФ облучения на кровь гемореологические показатели у больных ХПЛГ так и не достигали физиологической нормы. Данное обстоятельство объясняется спецификой патологического процесса, лежащего в основе гемореологических нарушений при данном заболевании.

Известно, что повышенная вязкость крови вызывает гипертрофию миокарда и повышает риск развития заболеваний сердца [15]. В условиях ХПЛГ это имеет большое значение. В соответствии с законом Пуазейля-Хагена коронарный кровоток снижается по мере увеличения вязкости крови. Снижая вязкость крови у больных ХПЛГ с помощью ФГТ и УФ облучения крови в комплексе с общепринятой терапией, можно добиться уменьшения легочной гипертензии

Таблица 5/Table 5

Реологические характеристики крови у больных хронической постэмболической легочной гипертензией 3-й (экспериментальной) группы до и после курса базисной терапии в сочетании с ультрафиолетовым облучением, $(M \pm m)$

Blood rheological characteristics in patients with chronic postembolic pulmonary hypertension of the $3^{\text {rd }}$ (experimental) group before and after the course of basic therapy combined with ultraviolet irradiation, $(M \pm m)$

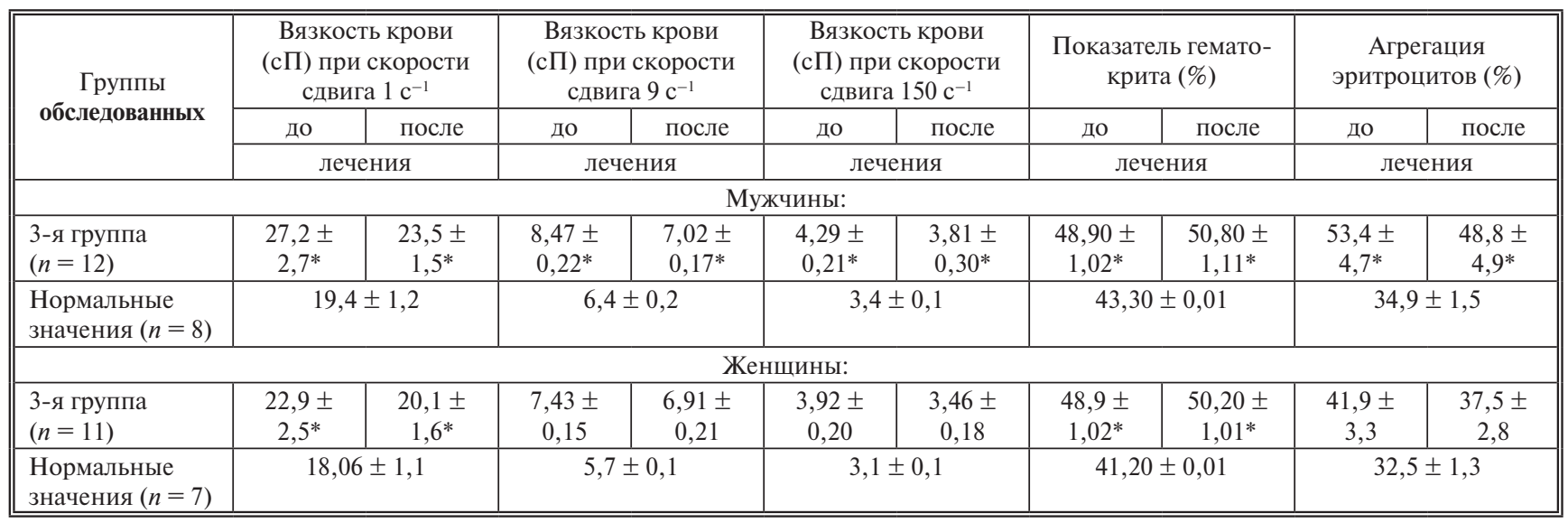

Примечание. ${ }^{*}-p<0,05$ - различия статистически значимы по сравнению с исходными (до лечения) значениями. Note. ${ }^{*}-p<0.05-$ the differences are statistically significant compared to baseline values (before therapy). 
и понижения сосудистого сопротивления. По данным A.M. Eaton с соавт., редукция вязкости крови приводит к снижению легочного сосудистого сопротивления на $41 \%$ и падению давления в легочной артерии на 44\% [16]. Оптическое излучение синего диапазона в целом способствует обеспечению и регуляции жизненно важных функций организма [17].

\section{Заключение}

Оценивая терапевтическую эффективность синего света и УФ воздействия на систему крови и кровообращение, можно предположить, что оптическое излучение синего света имеет более выраженное физиологическое действие, проявляющееся в его стойком, пролонгированном положительном эффекте на данные системы. УФ облучение при воздействии на кровь также способствует улучшению гемореологии и циркуляции крови и активирует рудиментарные механизмы, запускающие адаптационные системы организма, ранее не функционирующие.

\section{Литература \\ (п.п. 2; 15; 16 см. References)}

1. Карандашов В.И. Особенности оптического излучения в синем диапазоне спектра и перспективы использования его в практической медицине. Лазерная медицина. 2013; 17(2): 49-5.

3. Масляков В.В., Суханова О.А., Барсуков В.Г., Куркин К.Г., Суханов С.А. Возможности коррекции реологических свойств крови при колото-резаных ранениях груди (краткое сообщение). Патологическая физиология и экспериментальная терапия. 2017; 61(2): 72-5.

4. Пономаренко Г.Н. Физические методы лечения: Справочник. 4-е изд., перераб. и доп. СПб.; ВМедА; 2011.

5. Шостак Н.А., Кириенко А.И., Рябкова А.А., Бабадаева Н.М., Леонтьев С.Г. Легочная гипертензия как междисциплинарная проблема. Лечебное дело. 2005; (1): 17-24.

6. Клименко А.А., Шостак Н.А., Демидова Н.А., Новиков И.В. Хроническая постэмболическая легочная гипертензия: новые аспекты формирования и прогрессирования заболевания. Клиницист. 2011; (1): 14-8.

7. Илюхин Е.А., Золотухин И.А. Современное состояние проблемы профилактики рецидивов венозных тромбоэмболических осложнений. Флебология. 2017; 11(2): 83-90.

8. Чазова И.Е., Архипова О.А., Мартынюк Т.В. Легочная артериальная гипертензия в России: анализ 5-летнего наблюдения по данным Национального регистра. Терапевтический архив. 2019; 91(1): 10-31.

9. Филиппов Е.В. Легочная гипертензия: взгляд из прошлого в настоящее. РМЖ «Мед. Обозрение». 2019; 10 от 31.10.2019: 27-32.

10. Филатова Е.А., Войцеховский В.В., Григоренко А.А. Особенности эндобронхиальной микрогемоциркуляции у больных истинной полицитемией. Бюллетень физиологии и патологии дыхания. 2013; (47): 55-8.

11. Левичева Е.Н., Каменская О.В., Логинова И.Ю., Клинкова А.С., Булатецкая Л.М. Резервные возможности микроцирку- ляторного кровотока периферических тканей при циркуляторной гипоксии. Регионарное кровообращение и микроциркуляция. 2012; 11(3): 34-8.

12. Петухов Е.Б., Матюшенко А.А., Корнеев А.А., Александрова Н.П., Березов В.П., Малютина И.Г. Коррекция гипервязкости крови у больных хронической постэмболической легочной гипертензией методом инфузий УФ-облученной аутокрови. Грудная и сердечно-сосудистая хирургия. 1990; (10): 34-7.

13. Клименко Н.А., Ракша А.П., Демидова Н.А., Шостак Н.А. Патогенез и патоморфология хронической постэмболической легочной гипертензии. Лечебное дело. 2011; (3): 95-105.

14. Карандашов В.И., Петухов Е.Б. Ультрафиолетовое облучение крови. М.; Медицина, 1997.

17. Карандашов В.И., Петухов Е.Б., Зродников В.С. Квантовая терапия. М.; Медицина, 2004.

\section{References}

1. Karandashov V.I. Peculiarities of optic irradiation in the blue range of spectrum and perspectives of its application in practical medicine. Lazernaya meditsina. 2013; 17(2): 49-55. (in Russian)

2. Garsa Z.C.F., Born M., Hiblers P.A.J., van Riel N.A.W., Liebmann $\mathrm{J}$. Visible blue light therapy: molecular mechanisms and therapeutic opportunities. Cur Med Chem. 2018; 25(40): 5564-77. https://doi.or $\mathrm{g} / 10.2174 / 0929867324666170727112206$

3. Maslyakov V.V., Sukhanova O. A., Barsukov V.G., Kurkin K.G., Sukhanov S.A. Possibilities of correction of rheological properties of blood in stab wounds of the chest (brief report). Patologicheskaya Fiziologiya i Eksperimental'naya terapiya. 2017; 61(2): 72-5. (in Russian)

4. Ponomarenko G.N. Physical therapies: a handbook. $2^{\text {nd }}$ ed., revised and add. [Fizicheskie metody lecheniya: Spravochnik. 2-e izd., pererab. i dop]. Saint Petersburg; Voenno-meditsinskaya akademiya; 2011. (in Russian)

5. Shostak N.A., Kirienko A.I., Ryabkova A.A., Babadaeva N.M., Leontiev S.G. Pulmonary hypertension as an interdisciplinary problem. Lechebnoe delo. 2005; (1): 17-24. (in Russian)

6. Klimenko A.A., Shostak N.A., Demidova N.A., Novikov I.V. Chronic thromboembolic pulmonary hypertension: new aspects of the development and progression of the disease. Klinitsist. 2011; (1): 147. (in Russian)

7. Ilyukhin E. A., Zolotukhin I. A. Current state of the problem of prevention of relapses of venous thromboembolic complications. Flebologiya. 2017; 11(2): 83-90. (in Russian)

8. Chazova I.E., Arkhipova O.A., Martynyuk T.V. Pulmonary arterial hypertension in Russia: analysis of 5-year observation according to the National Register. Terapevticheskiy arkhive. 2019; 91(1): 10-31. (in Russian)

9. Filippov E.V. Pulmonary hypertension: a look from the past to the present. Breast cancer "Med. Review". [Legochnaya gipertenziya: vzglyad iz proshlogo v nastoyashchee. RMZH «Med. Obozrenie»]. 2019; 10 of 31.10.2019: 27-32. (in Russian)

10. Filatova E.A., Voytsekhovskiy V.V., Grigorenko A.A. Requliarities of endobronchial microcirculation in patients with polycythemia vera. Byulleten' fiziologii i patologii dykhaniya. 2013; (47): 55-8. (in Russian)

11. Levicheva E.N., Kamenskaya O.V., Loginova I.Yu., Klinkova A.S., Bulatetskaya L.M. Reserve capacities of microcirculatory blood flow in peripheral tissues in circulatory hypoxia. Regionarnoe krovoobrashchenie i mikrotsirkulyatsiya. 2012; 11(3): 34-8. (in Russian) 
DOI: 10.25557/0031-2991.2021.03.64-72

12. Petukhov E.B., Matyushenko A.A., Korneev A.A., Alexandrova N.P., Berezov V.P., Malyutina I.G. Correction of blood hyperviscosity in patients with chronic postembolic pulmonary hypertension by infusion of UV-irradiated autologous blood. Grudnaya i serdechnososudistaya khirurgiya. 1990; (10): 34-7. (in Russian)

13. Klimenko N.A., Raksha A.P., Demidova N.A., Shostak N.A. Pathogenesis and pathomorphology of chronic postembolic pulmonary hypertension. Lechebnoe delo. 2011; (3): 95-105. (in Russian)

14. Karandashov V.I., Petukhov E.B. Ultraviolet irradiation of blood. [Ul'trafioletovoe obluchenie krovi]. Moscow; Meditsina, 1997. (in Russian)
15. Devereux R.B., Drayer J.I., Chien S., Pickering T.G., Letcher R.L., DeYoung J.L., et al. Whole blood viscosity as a determinant of cardiac hypertension. Am J Cardiol. 1984; 54(6): 592-5. https://doi. org/10.1016/0002-9149(84)90255-8

16. Eaton A.M., Serota H., Kernodle G.W., Uglietta J.P., Crawford J., Fulkerson W.J. Pulmonary hypertension secondary to serum hyperviscosity in a patient with rheumatoid arthritis. $A m J$ Med. 1987; 82(5): 1039-45. https://doi.org/10.1016/00029343(87)90172-0

17. Karandashov V.I., Petukhov E.B., Zrodnikov V.S. Quantum therapy. [Kvantovaya terapiya]. Moscow; Meditsina, 2004. (in Russian)

\section{Сведения об авторах:}

Александрова Наталья Павловна, доктор биол. наук, проф., вед. науч. сотр. отдела медицинской реабилитации ГБУз города Москвы «Московский научно-практический центр медицинской реабилитации, восстановительной и спортивной медицины» Департамента здравоохранения города Москвы, e-mail: anatalyp@yandex.ru;

Погониенкова Ирэна Владимировна, доктор мед. наук, гл. внештатный специалист по медицинской реабилитации и санаторно-курортному лечению, директор ГАУЗ «Московский научно-практический центр медицинской реабилитации, восстановительной и спортивной медицины» Департамента здравоохранения города Москвы. 